\section{Killing creatures with kindness}

\section{Alan Holland}

The Case for Animal Experimentation: An Evolutionary and Ethical Perspective. By Michael Allen Fox. University of California Press: 1986. Pp. 262. \$18.95, £15.95.

There can be few people who have not benefited in one way or another from the results of experiments on animals. For this reason it seems unjust that researchers alone should bear the brunt of the hostility directed at such experiments. By the same token, however, if they are to retain public support for their endeavours, scientists have to accept the legitimacy of public scrutiny and ensuing legislative restrictions.

Those whose work involves animal experiments will be grateful to Michael Fox for his timely and valuable contribution to a debate which runs the risk of degenerating into a clash between vested interests and pressure groups. His aim is a "rational compromise" between the scientific community and animal protectionists, and his chosen brief is the defence of animal experimentation in biomedical and behavioural research. $\mathrm{Al}$ though this restriction of ground, taking in about 40 per cent of the whole, is no doubt reasonable, it does little to allay a general sense that the cause of experimentation is fragmenting under pressure. Lines are being drawn between the interests of industry and those of academia: research whose results are available for the benefit of all is more easily justified than research whose results, for political or economic reasons, are not open to scrutiny. Moreover, biomedical research, which is largely carried out on anaesthetized animals, is more easily defensible than behavioural research which mainly involves alert and conscious animals.

Two aspects of Fox's position illustrate nicely the obstacles in the way of rational compromise. One concerns basic research. Many researchers seem to accept that their work must ultimately be justified in terms of likely medical benefit. Fox demurs, taking the prospect of a significant advance in knowledge as justification enough, provided only that it "may conceivably" contribute to the alleviation of know it, human beings are the source and reference point of all value; second, on a denial that animals have moral rights, on the grounds that such rights can only develop in the context of a community of autonomous beings. On the other hand he holds that an animal's capacity for suffering, along with certain other features, makes it an appropriate object of moral concern and precludes cruel or inhumane treatment. Fox's reading of the evolutionary relationship between man and animal vindicates his ethical stance, but only thanks to his somewhat disconcerting rejection of Darwin's view that the difference is "one of degree and not of kind". Attention to the work of the "evolutionary epistemologists" (K. Lorenz, R. Riedl, D. Campbell) would, I surmise, yield an evolutionary perspective less congenial to his standpoint.

On the basis of these principles, Fox proceeds to show that most behavioural and biomedical experiments are morally acceptable. Through a series of illuminating case descriptions he illustrates also the important difference between retrospective and prospective assessment of the justification for an experiment. In describing the Harlows' experiments with
ANIMAL EXPERIMENTS IN MEDICAL RESEARCH
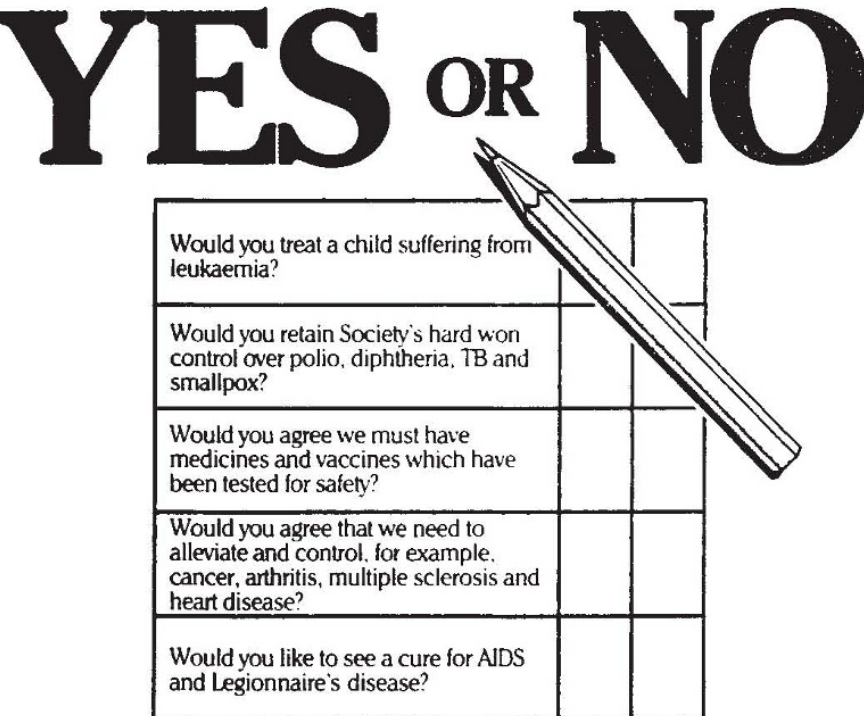

Animal experimentation has made an essential contribution to the control and eradication of serious diseases. Much more requires to be done-this work must continue.

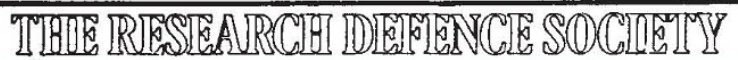
Safeguard your future

Researchers' response: a recent advertisement in a British newspaper.
RESEARCH DEFENCE SOCIETY, GROSVENOR GARDENSHOUSE. GROSVENOR GARDENS. LONDON SWIW OBS rhesus monkeys which involved severe maternal and sibling deprivation, for example, he is prompted to doubt whether "these nightmarish and regrettable experiments" would "pass muster before today's ethics review committees" (p. 103). But he regards the results obtained as a redeeming factor. Retrospectively the experiments lie on the borderline of acceptability, but they might not have been licensed in advance by his criteria because of uncertainty over the outcome. By contrast, Fox has little difficulty in justifying all of the experiments at Toronto's Hospital for Sick Children that he describes, because all promise at least moderate benefits and none involves more than moderate suffering. In these accounts, Fox rightly stresses the importance of spelling out the context of the experiments in order to arrive at a fair adjudication of their worth. More important still he goes on to show how it is only by understanding the demands of scientific inquiry in general - the need for controlled experiments, the requirement of repeatability, the need for statistically significant results - that we can avoid misconstruing a great deal of experimentation as gratuitous. His extensive review of the alternatives to the use of animals in research 
leads him to consider that the aim of abolition, even in the long term, is unrealistic. Indeed, by his principles, there need be no moral objection at all to experiments on anaesthetized laboratorybred animals continuing indefinitely.

Should we accept his principles? There is no doubt they will be hotly contested. His suggestion that man is something more than an animal is distinctly odd and even demonstrably misguided in so far as it rests on the allegedly paradoxical idea that man is both "part of" nature and yet stands "outside" it (p. 19). For there is surely no paradox in supposing that man belongs wholly within nature while at the same time having the capacity to reflect on his position. Again, Fox's crucial claim that animals lack intrinsic value seems to rest on the unsupported proposition that only beings capable of assigning value can have intrinsic value. What his theory of value does support is that animals only have intrinsic value if humans assign it to them. The most he can then argue is that they cannot be assigned an intrinsic value equal to that of humans.

Although marred occasionally by unworthy and on the whole irrelevant attacks on animal welfarists for being misanthropic, sentimental or irrational, a sincerity of tone runs through this book, nowhere more so than in the brave but unsuccessful attempt to reconcile the practice of experimentation with the claim to be humane; unsuccessful, because being humane implies being kind, and the deliberate infliction of avoidable suffering on an animal is not compatible with being kind to it. We must simply face the fact that the attempt to alleviate human suffering may involve the inhumane treatment of animals. Nor can the point be turned by the oft-repeated but hollow claim that animals stand to benefit as much as humans do. For the life of me I cannot see why an animal should be supposed to be more excited about being sacrificed to alleviate the suffering of another animal than it is about being sacrificed to alleviate the suffering of a human being.

Alan Holland is a Lecturer in the Department of Philosophy, University of Lancaster, Lancaster LA1 $4 Y T, U K$.

\section{ENGLISH \& AMERICAN} ACADEMIC BOOKS BY POST

to all countries

\section{S. BENARD}

74 Rochester Road, Aylesford, Kent ME20 7BJ, England

\section{Living alternatives}

\author{
James E. Lovelock
}

Origins of Life. By Freeman Dyson. Cambridge University Press:1986. Pp.81. £7.50, $\$ 7.95$.

Origins: A Skeptic's Guide to the Creation of Life on Earth. By Robert Shapiro. Summit, New York:1986. Pp.332. \$17.95.

EVERY so often a great physicist is perturbed by a curiosity about the meaning of life and is drawn in from that remote, personal Oort cloud where cosmology and subatomic particles can be considered in splendid detachment. One such was Erwin Schrödinger, whose small volume What is Life?, published by Cambridge University Press in 1946, still circulates and enlightens; it was, I would say, the book that most influenced my own thinking about science. Freeman Dyson's Origins of Life is modelled on Schrödinger's book, and like it is beautifully and economically composed.

Robert Shapiro has written about an entirely different search for the origins of life. Shapiro is a chemist intimately familiar with the experiments and theories concerned, and he writes like someone who lived when chemistry had soul, when chemicals could be handled personally and when it was permissible to wonder about their strange odours and crystalline forms. His book, he says, is intended to be an explanation "of what science does and does not understand about how life first began".

Schrödinger is best remembered for having sown the seeds of molecular biology. The great success of that undertaking has tended to make us forget that it was only part of his message, for Schrödinger also drew our attention to the fact that life processes are a legal avoidance of the second law. He asked the right question, "What is life?", rather than the equivocal one, "What are its origins?". Ancient happenings like the origin of life can never be known in detail by ordinary physical means. A message travelling through space and time attenuates until it is indecipherable. There is evidence about the state of the Earth when life began, but only because the persistence of life itself provides a limited but noise-free channel of communication back to our original ancestor. The geological record of the rocks of those times is almost absent.

Like a message passed by word of mouth, the chain of life back to the remote past carries precise but inaccurate information. But it is the only way we have to conjure up what the origin might have been. Shapiro describes the alternative guesses through the eyes of an enthusiastic explorer, with a friendly sceptic as a companion. It is so well done that one feels like a privileged visitor watching experiments in progress on the laboratory bench. Dyson goes further and provides a model of a pre-nucleic-acid chemical evolutionary system. He calls it his "toy" model, but it is full of insight as good and simple models should be.

The efforts to discover the origins of life may be as unrewarding as those to discover our own personal forebears. They resemble another recent scientific quest, one touched on by Shapiro, the search for life on Mars. Such expeditions start out looking for something imagined but not defined. We know there is no life on Mars; indeed we knew it long before the Viking spacecraft landed there. The value of such journeys comes indirectly. The discovery that Mars is not alive is the neutral background against which the Earth was more clearly seen to be a living planet. Similarly, the voyage into the past to the origins of life may never reach its goal, but the preparation for the expedition powerfully concentrates the mind on the nature and properties of life.

The two books are a constant reminder of how complicated life is, and that it has no definition. The successes of molecular biology are so beguiling that we forget the organism and its physiology. Schrödinger's disciples, who founded the church of molecular biology, have turned his wisdom to the dogma that life is self-replicating and corrects its errors by natural selection. There is much more to life than this naive truth, just as there is more to the Universe than atoms alone - grandmothers live and enjoy the shade of Lombardy poplar trees not knowing that they and the trees are deemed by this dogma to be dead. Looking in from the outside, Dyson sees homeostasis to be as important a characteristic of life as replication. I would go further and suggest that, as well as matter, life has bulk properties and needs to be considered on a planetary scale. It is so tightly coupled to its environment that the boundaries of life extend far beyond the organisms they enclose. A tree or a coral reef are both more than 90 per cent dead matter yet they are alive.

These two books are a continuation of the quest started by Darwin and Schrödinger. Implicitly, both are more about the meaning of life than about its origins and both deserve to be widely read. They are personal yet scholarly accounts of a difficult subject, and are wonderfully open in the way they illustrate how science is really done. They indicate an alternative view to the profitable but nonetheless narrow orthodoxy of molecular biology. Not least they are the best possible answer to the mischievous myths of Creationism, even though that was not their first intention.

James E. Lovelock, Coombe Mill, St Giles on the Heath, Launceston, Cornwall PL15 9RY, is an independent scientist. 